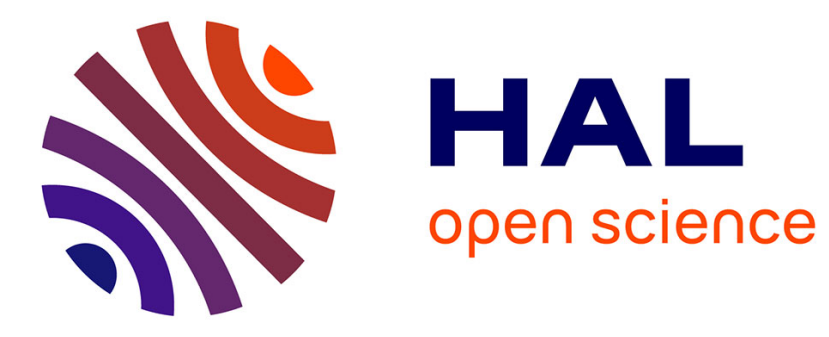

\title{
Dual Electroactivity in a Covalent Organic Network with Mechanically Interlocked Pillar[5]arenes
}

Benoit Colasson, Thomas Devic, Joël Gaubicher, Charlotte Martineau-corcos, Philippe Poizot, Vincent Sarou-kanian

\section{- To cite this version:}

Benoit Colasson, Thomas Devic, Joël Gaubicher, Charlotte Martineau-corcos, Philippe Poizot, et al.. Dual Electroactivity in a Covalent Organic Network with Mechanically Interlocked Pillar[5]arenes. Chemistry - A European Journal, 2021, 27 (37), pp.9589-9596. 10.1002/chem.202100558. hal03258960

\section{HAL Id: hal-03258960 https://hal.science/hal-03258960}

Submitted on 2 Jul 2021

HAL is a multi-disciplinary open access archive for the deposit and dissemination of scientific research documents, whether they are published or not. The documents may come from teaching and research institutions in France or abroad, or from public or private research centers.
L'archive ouverte pluridisciplinaire HAL, est destinée au dépôt et à la diffusion de documents scientifiques de niveau recherche, publiés ou non, émanant des établissements d'enseignement et de recherche français ou étrangers, des laboratoires publics ou privés. 


\title{
Dual Electroactivity in a Covalent Organic Network with Mechanically Interlocked Pillar[5]arenes
}

Benoit Colasson, ${ }^{*[a]}$ Thomas Devic, ${ }^{*[b]}$ Joël Gaubicher, ${ }^{[b]}$ Charlotte Martineau-Corcos, ${ }^{[c],[d]}$ Philippe Poizot, ${ }^{[b]}$ and Vincent Sarou-Kanian ${ }^{[d]}$

[a] Université de Paris, UMR 8601, LCPBT, CNRS, 45 rue des Saints Pères, F-75006 Paris, France. E-mail: benoit.colasson@parisdescartes.fr

[b] Institut des Matériaux Jean Rouxel (IMN), Université de Nantes, CNRS, 2 rue de la Houssinière, F-44322 Nantes, France. E-mail: thomas.devic@cnrs-imn.fr

[c] Institut Lavoisier de Versailles (ILV), Université de Versailles St Quentin, Université Paris-Saclay, 45 avenue des Etats-Unis, F-78035 Versailles, France

[d] CEMHTI UPR 3079, CNRS, Université d'Orléans, F-45071 Orléans, France

\begin{abstract}
The synthesis and characterization of a polyrotaxanated covalent-organic network (CON) based on the association between the viologen and pillar[5]arene $(\mathrm{P}[5] \mathrm{OH})$ units is reported. The mechanical bond allows for the irreversible insertion of $n$-type redox centers $(\mathrm{P}[5] \mathrm{OH}$ macrocycles) within a pristine structure based on $p$ type viologen redox centers. Both redox units are active on a narrow potential range and, in water, the presence of $\mathrm{P}[5] \mathrm{OH}$ greatly increases the electroactivity of the material.
\end{abstract}




\section{Introduction}

While mechanically interlocked molecules (MIMs) such as rotaxanes and catenanes have been primarily studied in solution, ${ }^{[1,2]}$ their integration in the solid state is a way to interface their many properties with current technologies and obtain emergent functional materials. ${ }^{[3,4]}$ The merging between MIMs and crystalline materials has been first set up in metal-organic frameworks (MOFs), allowing the precise positioning of MIMs on a long range order. ${ }^{[5-9]}$ The mechanical bond allows coupling the dynamics and switchable ability of MIMs with the robustness and high-order of MOFs, ${ }^{[10-16]}$ and could open the way for cooperative effects. Covalent-organic frameworks (COFs) and networks (CONs) has emerged as another class of open framework materials. ${ }^{[17-25]}$ As for the MOFs, the incorporation of MIMs in COFs opens new perspectives to develop materials with a higher level of complexity leading to improved functionalities and enhanced electronic, mechanical, photophysical or storage properties. However, to date, only one example of mechanically interlocked molecules incorporated within a purely organic extended material has been reported. ${ }^{[26]}$ In this material, cucurbi[7]turil macrocycles were successfully embedded via mechanical bonds in a polyviologen network and this association was found to enhance the photoluminescence efficiency as well as the hardness and Young modulus of the CON.

We report herein the synthesis and characterization of a polyrotaxanated organic network based on viologen units threaded into pillar[5]arene macrocycles $\left(P[5] \mathrm{OH}\right.$, see scheme 1). ${ }^{[27-28]}$ The mechanical bond allows for the irreversible association of $n$-type (oxidable) and $p$-type (reducible) redox centers (scheme 1). The interlocked structure of the material is confirmed by IR and in-depth solid state NMR studies and indirectly validated by the characterization with High-Resolution Electro-spray ionization Mass Spectrometry (HR-ESIMS) of a molecular counterpart. By combining solid state electrochemistry and operando UV-vis spectroscopy, we show that both the $p$-type and $n$-type redox units found in this material are active on a relatively narrow potential range $(\sim 1 \mathrm{~V})$, both in anhydrous and aqueous conditions and that in water the presence of $\mathrm{P}[5] \mathrm{OH}$ greatly increases the electroactivity of the material.

\section{Results and Discussion}

The combination of the viologen unit and $\mathrm{P}[5] \mathrm{OH}$ macrocycle in the targeted material was selected for several reasons: i) viologen-based COFs have been already reported; ${ }^{[26,29-32]}$ ii) the viologen unit and $\mathrm{P}[5] \mathrm{OH}$ interact with each other and form pseudo-rotaxane structures in solution; ${ }^{[27-28]}$ iii) with the aim at exploiting their redox activity in the solid state, the bipyridinium fragment can be reduced in two steps by oneelectron reversible processes while the pillar[5]arene macrocycle is electrochemically active and can exchange up to 10 electrons both in solution and in the solid state (see scheme 1 ). ${ }^{[33-34]}$

Synthesis of the interlocked and non-interlocked materials. Two extended materials were synthesized and characterized. The targeted material CON-2@P[5]OH-X (X = anion) is composed of redox active P[5]OH macrocycles incorporated into a viologen-based network via a mechanical bond. To evaluate the influence of the $\mathrm{P}[5] \mathrm{OH}$ macrocycles on the electrochemical performances of the material, the viologen material deprived of $\mathrm{P}[5] \mathrm{OH}$ CON-2-X was also synthesized (see Scheme 2). The ?-keto-enamine linker was chosen to ensure the chemical stability of these materials (especially towards hydrolysis). ${ }^{[35-36]}$

CON-2-X (X = $\mathrm{ClO}_{4}$ or $\left.\mathrm{PF}_{6}\right)$ was obtained by the condensation of 1,1'-bis(4-aminophenyl)-[4,4'-bipyridine]-1,1'diium dianion, $\mathbf{2}(\mathbf{X})_{2}$, and 2,4,6-triformylphloroglucinol $\mathbf{3}$ in $\mathrm{N}, \mathrm{N}$-dimethylacetamide (DMA) at $90^{\circ} \mathrm{C}$ (Scheme 2). After washing to remove any traces of unreacted reagents and soluble intermediates and drying under vacuum at $100^{\circ} \mathrm{C}$ to remove the solvents, $\mathbf{C O N - 2 - X}$ was obtained as a deep red solid in $92 \%$ yield (for $\mathrm{X}=\mathrm{ClO}_{4}$ ). This solid is insoluble in all the solvents tested: water, DMA, N,N-dimethyformamide, acetone, acetonitrile, in line with its 
polymeric structure. Note that during the course of this work, a crystalline version of this material was obtained by a liquid-liquid interfacial polymerization, ${ }^{[26]}$ although in our synthetic conditions only amorphous solids were obtained. The spectroscopic data for CON-2-X are in good agreement with the previously reported material. Especially, the FTIR spectrum (Figure S1) shows characteristic stretching bands at $01612 \mathrm{~cm}^{-1}$ for $\mathrm{C}=\mathrm{O}$, 目 $=1580$ $\mathrm{cm}^{-1}$ for $\mathrm{C}=\mathrm{C}$ and $\mathrm{O}=1251 \mathrm{~cm}^{-1}$ for $\mathrm{C}-\mathrm{N}$ demonstrating that the linker is in the l-keto-enamine form. CON-2-X was further characterized by solid state NMR spectroscopy (vide infra). The design of the final material CON2@P[5]OH-X is based on the intermolecular association of the viologen monomer $\mathbf{2}(\mathbf{X})_{2}$ with P[5]OH before the polymerization takes place. Kinetically, the association is much faster than the formation of the new covalent bonds. Thermodynamically, the formation of the pseudo-rotaxane was confirmed by the titration in acetone- $d_{6}$ of $2\left(\mathrm{PF}_{6}\right)_{2}$ with $\mathrm{P}[5] \mathrm{OH} 1$ at room temperature (Figures S2-S3). The association constant $K$ was found to be ca. $850 \pm 140 \mathrm{M}^{-1}$. According to this association constant, with the concentration (ca. $0.15 \mathrm{M}$ ) used in the synthesis of $\mathrm{CON}-2-\mathrm{X}$, a $\mathrm{P}[5] \mathrm{OH} / \mathbf{2}\left(\mathrm{PF}_{6}\right)_{2}$ ratio of 2 would ensure that $99 \%$ of the viologen monomer is associated with a macrocycle. The change in temperature and solvent between the titration experiment and the synthesis may affect the value of $K$. The same calculation made with a value ten folds lower still gives $94 \%$ of associated monomer available for the polymerization. Therefore, CON-2@P[5]OH-X was obtained in the same conditions used for CON-2-X except for the addition of 2 equivalents of P[5]OH 1. CON-2@P[5]OH-X was obtained as a red solid in good yield after abundant washing to remove in particular the excess of $\mathrm{P}[5] \mathrm{OH}$ and dried under vacuum at $100{ }^{\circ} \mathrm{C}$. As CON-2-X, CON-2@P[5]OH-X is insoluble in all tested organic solvents, and amorphous (Figure S6). Attempts to improve the crystallinity, notably by playing on the nature of the anion $\mathrm{X}$, were unsuccessful. The first evidence of the incorporation of $\mathrm{P}[5] \mathrm{OH}$ macrocycles in the material came from the FTIR analysis. Besides the characteristic bands at $1614 \mathrm{~cm}^{-1}, 1577 \mathrm{~cm}^{-1}$ and $1261 \mathrm{~cm}^{-1}$ also observed for CON-2-X indicating that the polymerization occurred, additional or more intense bands, attributed to $\mathrm{P}[5] \mathrm{OH}$ are present at $779 \mathrm{~cm}^{-1}, 930$ $\mathrm{cm}^{-1}, 1192 \mathrm{~cm}^{-1}$ and $1424 \mathrm{~cm}^{-1}$ (Figures S4-S5). Elemental analysis of CON-2-PF 6 and CON-2@P[5]OH-PF 6 confirms the presence of $\mathrm{P}[5] \mathrm{OH}$ (Tables S1-S3). The C/N ratio of 6.2 (6.0 for the calculated value) measured for CON-2$\mathbf{P F}_{6}$ was logically found at a higher value of 11.4 for CON-2@P[5]OH-PF. Since the ideal 1:1 viologen:P[5]OH stoichiometry in the solid corresponds to a $\mathrm{C} / \mathrm{N}$ ratio of 13.5 , the measured $\mathrm{C} / \mathrm{N}$ ratio also indicates that the actual stoichiometry is 1:0.7. Although thermogravimetric analyses indicated the presence of ca. $5 \mathrm{wt} \%$ of solvent in both solids (Figure S7), krypton sorption experiments carried out a $77 \mathrm{~K}$ revealed no accessible microporosity (Figure S8). Both solids were produced as brittle materials, with polydisperse micrometric particles presenting a vitreous aspect (see scanning electron microscopy images Figure S9). When CON-2@P[5]OH-X was suspended and sonicated for hours in acetone or methanol in which $\mathrm{P}[5] \mathrm{OH}$ is well-soluble, no modification of the FTIR spectrum was noted. At this stage, the strong association of $\mathrm{P}[5] \mathrm{OH}$ macrocycles within the viologen network is demonstrated, but other experimental evidences are needed to confirm the rotaxane-like structure. This structure was unambiguously proved by an indirect method and by in-depth solid state NMR and electrochemical studies.

Indirect proof of structure. An indirect experimental confirmation of the existence of mechanical bonds in the structure of CON-2@P[5]OH-X was obtained with the synthesis of a soluble discrete counterpart, which could be more easily characterized by techniques adapted to molecular compounds. Molecular equivalents of CON-2-Cl and CON-2@P[5]OH-PF6 $\left(8(\mathrm{Cl})_{6}\right.$ and 8@P[5]OH(PF6)6 respectively, see scheme 3) were thus prepared. The syntheses and characterizations $\left({ }^{1} \mathrm{H},{ }^{13} \mathrm{C}, \mathrm{HSQC}, \mathrm{HMBC}\right.$ and COSY NMR, FTIR and HR-ESIMS) of all the intermediates and the two final compounds are described in the supplementary information (Figures S10-S44). The key step for the synthesis of $\mathbf{8}(\mathrm{Cl})_{6}$ and $\mathbf{8} @ \mathbf{P}[5] \mathbf{O H}\left(\mathrm{PF}_{6}\right)_{6}$ relies on the final condensation of 2,4,6triformylphloroglucinol $\mathbf{3}$ with three equivalents of an unsymmetrical viologen unit $\mathbf{7}(\mathbf{X})_{2}$ bearing at one end an aniline function to react with the aldehyde and at the other end a 3,4,5-trimethoxybenzyl group which in 
8@P[5]OH( $\left.\mathrm{PF}_{6}\right)_{6}$ plays the role of a stopper and prevents the unthreading of the macrocycle $\mathrm{P}[5] \mathrm{OH} .{ }^{[37-38]} \mathrm{The}$ conditions of the reaction (solvent, concentrations, temperature, reaction time) to yield $\left.8 @ P[5] \mathbf{O H}_{(\mathbf{P F}}\right)_{6} \mathbf{W e r e}$ kept identical as for the synthesis of $\mathbf{C O N}-\mathbf{2} @ \mathbf{P}[5] \mathbf{O H}-\mathbf{P F}_{6}$. The only difference was for the $\mathrm{P}[5] \mathrm{OH} / \mathbf{2}\left(\mathbf{P F}_{6}\right)_{\mathbf{2}}$ ratio which was fixed at 1 instead of 2 for an easier isolation. This choice does not jeopardize the conclusions since a lower ratio is detrimental to the degree of rotaxanation.

${ }^{1} \mathrm{H}$ NMR spectrum of $\mathbf{8}(\mathbf{C l})_{6}$ in DMSO- $d_{6}$ revealed the presence of both $C_{3 h}$ and $C_{s}$ isomers in a ca. 2:3 ratio as already observed for related compound (see Figures S28 and S29). ${ }^{[23,39]}$ Nevertheless, the spectra in DMSO- $d_{6}$ and in $\mathrm{CD}_{3} \mathrm{OD}$ are quite simple because most of the peaks for equivalent protons on the two isomers overlap. The chemical structure of $\mathbf{8}(\mathbf{C l})_{6}$ was further confirmed by HR-ESIMS analysis with the presence of 4 major peaks at $\mathrm{m} / \mathrm{z}=233.5954, \mathrm{~m} / \mathrm{z}=280.1130, \mathrm{~m} / \mathrm{z}=349.8895$ and $\mathrm{m} / \mathrm{z}=466.1837$ corresponding to the hexa-, penta-, tetra- and tri-cationic species respectively (Figures S33-S37). As for CON-2-X and CON-2@P[5]OH-X, the comparison of the FTIR spectra clearly highlights the presence of the P[5]OH macrocycle in 8@P[5]OH(PF6) (Figure S38). The ${ }^{1} \mathrm{H}$ NMR spectrum in DMSO-d 6 of $8 @ \mathrm{P}[5] \mathrm{OH}\left(\mathrm{PF}_{6}\right)_{6}$ is much more complicated (see Supporting Information for a detailed discussion). Nevertheless, the comparison between the ${ }^{1} \mathrm{H} N M R$ spectra of $\mathbf{8}(\mathbf{C l})_{6}$ and 8@P[5]OH( $\left.\mathbf{P F}_{6}\right)_{6}$ is informative (Figure S39). Here again, the analysis of the $\mathrm{N}-\mathrm{H}$ resonances around $13 \mathrm{ppm}$ indicates the presence of two spatial arrangements involving the keto- enamine core in the same 2:3 ratio.

In the region of the spectra between 6 and 7 ppm, many peaks are present for $\mathbf{8} @ \mathbf{P}[\mathbf{5}] \mathbf{O H}\left(\mathbf{P F}_{6}\right)_{6}$ whereas it is an empty zone for $\mathbf{8}(\mathbf{C l})_{6}$. This can be explain by an upfield shift for some resonances of the protons of the viologen units due to the presence of the polyaromatic $\mathrm{P}[5] \mathrm{OH}$ macrocycle. Definitive evidence of the poly-rotaxane structure of 8@P[5]OH $\left(\mathrm{PF}_{6}\right)_{6}$ (exact mass is 4101.8886) was obtained by HR-ESIMS characterization (Figure 1 and Figures S40-S44). The spectrum is dominated by 3 major peaks at $\mathrm{m} / \mathrm{z}=538.8549, \mathrm{~m} / \mathrm{z}=675.6191$ and $\mathrm{m} / \mathrm{z}=$ 880.7642 which correspond to the proposed structure for $8 @ \mathrm{P}[5] \mathrm{OH}\left(\mathrm{PF}_{6}\right)_{6}$ with the loss of 6, 5 and $4 \mathrm{PF}_{6}$ anions respectively (see Supporting Information for more details). A fourth peak at $\mathrm{m} / \mathrm{z}=1222.6705$ corresponding to the tricationic species (loss of $3 \mathrm{PF}_{6}$ anions) is also visible. In addition, each peaks at $\mathrm{m} / \mathrm{z}=1222.6705, \mathrm{~m} / \mathrm{z}=$ 880.7642 and $\mathrm{m} / \mathrm{z}=675.6191$ is associated with a minor peak at $\mathrm{m} / \mathrm{z}=1173.6775, \mathrm{~m} / \mathrm{z}=844.2715$ and $\mathrm{m} / \mathrm{z}=$ 646.4249, respectively, corresponding formally to one $\mathrm{PF}_{6}$ anion less whose charge is compensated by an in situ one electron reduction of a viologen unit. Finally, the HR-ESIMS spectrum also shows the presence of a minor product bearing only two $\mathrm{P}[5] \mathrm{OH}$ macrocycles (peaks at $\mathrm{m} / \mathrm{z}=437.1568, \mathrm{~m} / \mathrm{z}=553.5812, \mathrm{~m} / \mathrm{z}=728.2183$ and $m / z=1019.2775)$. This indicates unambiguously that 8@P[5]OH(PF6)6 is a [4]-rotaxane species, and hence indirectly confirms the rotaxane-like association between the $\mathrm{P}[5] \mathrm{OH}$ macrocycles and the viologen units in CON2@P[5]OH-X for which synthesis was done in similar conditions. This analysis further agreed very well with the high ratio of rotaxanation as obtained by elemental analysis.

Solid state NMR characterization. The presence of $\mathrm{P}[5] \mathrm{OH}$ was further confirmed by solid-state ${ }^{13} \mathrm{C},{ }^{1} \mathrm{H}$ and ${ }^{14} \mathrm{~N}$ magic-angle spinning (MAS) NMR. The ${ }^{13} \mathrm{C}$ cross-polarization (CPMAS) NMR spectrum of CON-2@P[5]OH-PF 6 (Figure 2) is indeed the sum of the contributions from CON-2-PF6 and $\mathrm{P}[5] \mathrm{OH}$ 1. The spectrum of $\mathrm{P}$ [5]OH can be easily attributed by comparison with the ${ }^{13} \mathrm{C}$ NMR spectrum recorded in solution. ${ }^{[0]}$ It is then particularly clear that the peak at ca. 27 ppm, which corresponds to the carbon atoms of the bridging methylene units in $\mathrm{P}[5] \mathrm{OH}$, is present in CON-2@P[5]OH-PF 6 . In the 2D ${ }^{1} \mathrm{H}^{13} \mathrm{C}$ MAS NMR spectrum (Figure S45), this ${ }^{13} \mathrm{C}$ resonance has a correlation peak of strong intensity with the proton signal at ca. $3 \mathrm{ppm}$, which therefore corresponds to the $\mathrm{CH}_{2}$ protons. A correlation peak of weaker intensity (i.e., longer $\mathrm{C} \cdots \mathrm{H}$ distance) with the protons at around $5.5 \mathrm{ppm}$ is observed, which correspond to the neighboring aromatic protons $\mathrm{H}_{\mathrm{b}}$ of the macrocycle.

The ${ }^{1} \mathrm{H}$ NMR spectra of all samples contain very broad resonances and are therefore less informative (see Supporting Information for a detailed discussion). Interestingly, the ${ }^{1} \mathrm{H}$ resonance centered at ca. $13 \mathrm{ppm}$, 
corresponding to the enamine N-H protons is observed for both solids (Figure S46), confirming the proposed structure. Also, the $2 \mathrm{D}^{1} \mathrm{H}-{ }^{1} \mathrm{H}$ MAS NMR experiments (Figure S49) indicate that the sample is single-phased, with very close spatial proximity for all protons, arguing for a rotaxane-like structure rather than a simple physical mixture of both components.

Finally, ${ }^{14} \mathrm{~N}$ NMR spectroscopy was considered. ${ }^{14} \mathrm{~N}$ is an interesting nucleus as it has $99.6 \%$ natural abundance. ${ }^{14} \mathrm{~N}$ has a nuclear spin of 1 , and, provided suitable NMR technique is employed (see experimental section for further details of the indirect detection of ${ }^{14} \mathrm{~N}$ signal), ${ }^{[41]}{ }^{1} \mathrm{H}-{ }^{14} \mathrm{~N} 2 \mathrm{D}$ NMR spectrum can be recorded in a greatly reduced experimental time (few hours compared to few days for a ${ }^{1} \mathrm{H}-{ }^{15} \mathrm{~N} 2 \mathrm{D}$ NMR spectrum at natural abundance). We first recorded the ${ }^{1} \mathrm{H}^{-1}{ }^{14} \mathrm{~N} 2 \mathrm{D}$ MAS NMR spectra of the two models $\mathbf{8}(\mathbf{C l})_{6}$ and $8 @ P[5] \mathbf{O H}_{(}\left(\mathrm{PF}_{6}\right)_{6}$ to obtain a fingerprint of the mechanical bond between $\mathrm{P}[5] \mathrm{OH}$ and the viologen (Figure S50). With $\mathbf{8}(\mathbf{C l})_{6}$, two different nitrogen atoms are present: the first one $(\mathrm{N}-\mathrm{H})$ with a chemical shift of ca. -160 ppm correlates with the enamine proton at $13 \mathrm{ppm}$ and the second one ( $\left.\mathrm{N}_{\text {viologen }}\right)$ with a chemical shift of ca. -180 ppm correlates with the viologen protons in the aromatic region of the spectrum. These two nitrogen atoms resonances are also found the spectrum recorded for $8 @ P[5] \mathbf{O H}\left(\mathrm{PF}_{6}\right)_{6}$. In addition, a new cross peak involving the $\mathrm{N}_{\text {viologen }}$ atom is present with protons having a chemical shift around $6 \mathrm{ppm}$. Since this correlation is only seen in presence of $\mathrm{P}[5] \mathrm{OH}$, it can unambiguously be attributed to the rotaxane structure. The same ${ }^{1} \mathrm{H}^{-14} \mathrm{~N} 2 \mathrm{D}$ NMR experiment was carried out for CON-2-PF6 and CON-2@P[5]OH-PF 6 (Figure 3).

The nitrogen atoms have similar chemical shift (ca. $-160 \mathrm{ppm}$ for the $\mathrm{N}-\mathrm{H}$ atom and - $180 \mathrm{ppm}$ for the $\mathrm{N}_{\text {viologen). }}$ ). More importantly, the additional cross-peak observed for $\mathbf{8} @ \mathbf{P}[5] \mathbf{O H}\left(\mathrm{PF}_{6}\right)_{6}$ is also present in the spectrum of CON-2@P[5]OH, confirming the rotaxanation of $\mathrm{P}[5] \mathrm{OH}$ and the viologen unit.

Solid state electrochemical studies. $\mathrm{CON}-2-\mathrm{ClO}_{4}$ and $\mathrm{CON}-2 @ \mathrm{P}[5] \mathrm{OH}-\mathrm{ClO}_{4}$ are among few materials that can in principle exchange both cations and anions in a narrow potential window. ${ }^{[42]}$ In addition, their relatively poor solubility offers the possibility to compare their solid-state electrochemical response both in organic and aqueous electrolytes. For all these studies, $\mathrm{ClO}_{4}$ and $\mathrm{Cl}$ counter ions were preferred over $\mathrm{PF}_{6}$, that can react with phenolic protons and water with concomitant formation of HF. These experiments were further complemented by UV-Vis spectro-electrochemical studies on the molecular analogues $\mathbf{8}(\mathrm{Cl})_{6}$ and $\mathbf{8} @ \mathbf{P}[\mathbf{5}] \mathbf{O H}(\mathbf{C l})_{6}$ to confirm the redox reactions at play.

Composite electrodes were first prepared by mixing the materials with a conductive carbon additive and PTFE binder (see Supporting Information for details). Figure 4a compares the cyclic voltammetry of both $\mathrm{CON}^{-2-\mathrm{ClO}_{4}}$ and CON-2@P[5]OH-ClO 4 in $0.5 \mathrm{M}, 1 \mathrm{M}$ and $3.5 \mathrm{M} \mathrm{LiClO}_{4}$ in propylene carbonate (PC). CON-2@P[5]OH-ClO shows three broad peaks (referred to as 1, 2 and 3) at ca. 2.8, 2.5 and 2.2 V vs. Li/ $\mathrm{Li}^{+}$. Considering the average of the anodic and cathodic peak potentials as the apparent redox potential, the increase of the electrolyte concentration results in a decrease of 2 and 3 in a near to linear fashion (Figure S51). This trend suggests an anion $\left(\mathrm{ClO}_{4}{ }^{-}\right)$assisted redox process which can therefore be ascribed to the stepwise reduction of the viologen unit. ${ }^{[43-}$ 44] The cycling voltammetry of $\mathbf{C O N}-2-\mathbf{C l O}_{4}$ in $1 \mathrm{M} \mathrm{LiClO}_{4}$ shows two reversible redox events at 2.7 and $2.3 \mathrm{~V}$ vs. $\mathrm{Li} / \mathrm{Li}^{+}$, pertaining to the viologen electroactivity with concomitant release of the $\mathrm{ClO}_{4}{ }^{-}$anions (Figure $4 \mathrm{a}$ ). ${ }^{[43,45]} \mathrm{The}$ electrochemical redox mechanism at play was further confirmed from experiments conducted on the corresponding molecular counterparts $\left(\mathbf{8}(\mathbf{C l})_{6}\right.$ and $\left.8 @ P[5] O H(C l)_{6}\right)$ deposited on conductive transparent FTO substrates. Cyclic voltammetry measurements were first performed to insure the electrochemical response was similar to that of the corresponding COF (Figure S52), and further UV-Vis spectroelectrochemical studies confirmed that the redox events 2 and 3 are associated with the stepwise reduction of the viologen units (See Figure S53 and supporting Information for details). 
Interestingly, in $1 \mathrm{M} \mathrm{LiClO}_{4}$, potentials associated with the reduction of viologen are clearly down shifted for CON2-ClO ${ }_{4}$ (Figure 4a). This observation suggests the presence of a more electron-rich environment around the viologen units in the case of $\mathrm{CON}-2 @ \mathrm{P}[5] \mathrm{OH}-\mathrm{ClO}_{4}$, which is in complete agreement with the presence of the rotaxane motif. Process 1 is not observed for $\mathrm{CON}^{2}-\mathrm{ClO}_{4}$ (Figure 4a) and is therefore associated with the electroactivity of the phenolate/quinone redox couple of the macrocyclic unit. Its potential of nearly $2.8 \mathrm{~V}$ in $1 \mathrm{M}$ $\mathrm{LiClO}_{4}$ matches that found by Chen, ${ }^{[34]}$ Dominko, ${ }^{[46]}$ and us (Figure S55) with pillarquinone and calix[4]arene respectively in another organic electrolyte (1M LiPF 6 in 1:1 ethylenecarbonate:dimetylcarbonate).

Quite surprisingly, the potential of process 1 appears nearly invariant with the electrolyte concentration (Figure S51). Although, more experiments are required to better understand this peculiar behavior, we propose in the frame of the mechanically interlocked pillararene macrocycles that the negative charge of the phenolate groups are compensated in zwitterion-type interactions by the positive charge of the viologen cations rather than those of the supporting electrolyte. It is also noted that the electroactivity of $\mathbf{C O N}-\mathbf{2}-\mathbf{C l O}_{4}$ is characterized by much more defined and intense CV peaks (Figure 4a) which suggests that the overall kinetics of $\mathrm{CON}-2 @ \mathrm{P}^{2}\left[\mathbf{5}_{\mathrm{OH}}-\mathrm{ClO}{ }_{4}\right.$ is strongly impeded in this medium.

The specific gravimetric capacities $(Q$, the amount of charge exchanged per mass of redox-active material) were derived from these CV curves on charge (oxidation) to discard electrons associated with possible $\mathrm{H}_{2}$ formation on discharge (reduction) in aqueous media. This enables to determine whether these redox events occur only at the surface or within the bulk of the solids, and ultimately evaluate the potentiality of these compounds as active materials for electrochemical energy storage.

Overall, the specific capacity (Figure 5) of $\mathbf{C O N - 2 - C l O}$ is nearly twice higher than that of $\mathbf{C O N}-\mathbf{2} @ \mathbf{P}[\mathbf{5}] \mathbf{O H}-\mathbf{C l O}{ }_{4}$ : upon subtraction of the charge associated with the conductive additive double layer capacitance, the overall capacity on charge (oxidation) comes to $20.6 \mathrm{mAh} . \mathrm{g}^{-1}$ - that represents $25 \%$ of the theoretical capacity considering 2 electrons per viologen moiety. In comparison, that of $\mathbf{C O N}-\mathbf{2} @ P 5[O H]-\mathbf{C l O}_{4}$ is $7.6 \mathrm{mAh} \mathrm{g}^{-1}-$ that is only $3 \%$ of the theoretical capacity considering an additional 10 electrons per $\mathrm{P}[5] \mathrm{OH}$ unit (5\% considering 5 electrons per macrocycle). These observations suggest strong kinetic inhibitions from poor electron and/or ion diffusivity preventing the accessibility of all redox centers (i.e. the solid bulk) with organic electrolytes.

The electrochemical behavior of these two compounds were thus evaluated in aqueous electrolyte $1 \mathrm{M} \mathrm{LiClO}_{4}$ (Figure 4b). Although the overall profiles and potential shift of the viologen are similar to that encountered in PC (Figure 4a) some specificities appear. First, in aqueous media the peak associated with P[5]OH is further apart from the first viologen peak (approx. $+380 \mathrm{mV}$ ) than in PC (approx. + $260 \mathrm{mV}$ ). More importantly, the electrochemical activity of $\mathbf{C O N - 2 @ P [ 5 ] O H - C l O} 4$ is strongly enhanced (+ $470 \%)$ in aqueous vs. PC electrolyte as it steps from nearly 7.6 to $43.4 \mathrm{mAh} \mathrm{g}^{-1}$ upon correction from the conducting additive (Figure 5, green bars). Interestingly, this gain of capacity does not stem from the sole increase of the $\mathrm{P} 5[\mathrm{OH}]$ electroactivity. Indeed, relatively, the latter is nearly the same in aqueous media (52\% of the overall capacity on charge) and in PC (48\%), suggesting that such an enhancement primarily results from the higher ion diffusivity in water. However, the beneficial effect of the aqueous electrolyte is not as intense in the case of the CON-2 since the increase of the specific capacity only reaches $21 \%$, leading to a reversal of the specific capacity order with $\mathrm{Q}\left(\mathrm{CON}_{-}-\mathbf{2}-\mathrm{ClO}_{4}\right)<$ $\mathrm{Q}\left(\mathrm{CON}-2 @ \mathrm{P}[5] \mathrm{OH}-\mathrm{ClO}_{4}\right)$ (Figure 5). Such a difference could be related to the hydrophilic nature of the $\mathrm{P}[5] \mathrm{OH}$, which might favor the diffusion of the aqueous electrolyte in CON-2@P[5]OH-ClO accessibility of the redox centers within the bulk of the solid. The measured capacity, even in aqueous electrolytes, remains lower than the expected one (ca $225 \mathrm{mAh} \mathrm{g}^{-1}$ considering a composition of one viologen ( 2 electrons) for $0.7 \mathrm{P}[5] \mathrm{OH}$ (10 electrons)). This mainly results from the limited activity of the hydroquinone units: the relative intensities of the currents associated with the viologen and the $\mathbf{P}[\mathbf{5}] \mathbf{O H}$ units are indeed ca $1: 1$ 
whereas a value of 1:3.5 is expected if all redox centers were active. A discrepancy between with the expected ratio of redozx activity has already been observed in literature for COFs containing two redox units covalently linked. ${ }^{[47,48]}$ In our case, this effect should be even more pronounced since the P[5]OH macrocycles are not covalently attached and therefore even more insulated from an electronic standpoint, whereas the viologen units are involved in a rather conjugated extended framework (the CON itself). Improvements of the activity of $\mathbf{P}[5] \mathrm{OH}$, and of the whole solid, might be obtained by improving the long range order as recently shown by Dichtel et al., ${ }^{[49]}$ as well as downsizing the particles, nanostructuration and optimization of the formulation of the electrode, ${ }^{[42]}$ notably by playing with the carbon additive. ${ }^{[47,48]}$ The mechanical bond nevertheless here appears as an appealing method to produce materials combining both $\mathrm{n}$ - and $\mathrm{p}$-type redox centers active in a rather narrow potential range $(<1 \mathrm{~V})$, where most COFs based on the covalent bonding of two redox active moieties usually require a far larger potential window (typically $\sim 3 \mathrm{~V})^{[47-53]}$ which is unsuitable for practical applications in ion batteries.

\section{Conclusion}

The insertion of $\mathrm{P}[5] \mathrm{OH}$ macrocycles in the structure of a viologen-based $\mathrm{CON}$ via mechanical bonds has been realized. The presence of $\mathrm{P}[5] \mathrm{OH}$ in the matrix of the solid was proved by $I R$, elemental analysis and $1 \mathrm{D}{ }^{13} \mathrm{C}$ MAS NMR experiments. The rotaxane-like association of the two components was evidenced by several means: i) the use of molecular models and the unambiguous proof obtained with HR-ESIMS that in the conditions of the formation of the solid, the rotaxanation is greatly favored, ii) the comparison of $2 \mathrm{D}^{1} \mathrm{H}-{ }^{14} \mathrm{~N} M A S$ NMR spectra for which the fingerprint of the rotaxane structure is clearly identified in the final material. Importantly, the strategy consisting of using the mechanical bond in CON chemistry is here used for the first time to associate n-type and p-type redox centers. Solid electrochemical studies showed that both redox centers are active on a relatively narrow potential range ( $1 \mathrm{~V}$ ) above $2.2 \mathrm{~V}$ vs Li, hence suggesting that such type of materials might be of interest as positive electrode materials for ion-batteries. In water, the presence of $\mathrm{P}[5] \mathrm{OH}$ increase by ca. $74 \%$ the specific capacity compared to the pristine $\mathrm{CON}$ deprived of $\mathrm{P}[5] \mathrm{OH}$. Although modest performances have been obtained so far, much improvements are expected from a better structuration of the material and formulation of the electrodes. COF are promising materials to develop organic based electrodes ${ }^{[23,54]}$ in the context of nontoxic and sustainable electron storage technologies. ${ }^{[42,55-57]}$ The strategy proposed in this work brings leads to tackle several challenges: i) increase the density of redox centers, ii) association of different well-defined redox centers, and iii) fine tuning of the potentials. The exploitation of other electroactive COFs and macrocycles reported to date could help to solve these matters.

\section{Acknowledgements}

$\mathrm{CMC}$ is grateful for financial support from the Institut Universitaire de France (IUF). Financial support from the IR-RMN-THC Fr3050 CNRS for conducting the research is gratefully acknowledged. Stéphane Grolleau (IMN) is thanked for thermogravimetric and Xe sorption analyses, and Patrice Gerardo (LCPBT) for HR-ESIMS measurements.

Keywords: covalent-organic network $\bullet$ rotaxane $\bullet$ viologen $\bullet$ pillar[5]arene $\bullet$ electroactive solid 


\section{References}

a) C. O. Dietrich-Buchecker, J. P. Sauvage, J. P. Kintzinger, Tet. Lett. 1983, 24, 5095-5098; b) J. F. Stoddart, Chem. Soc. Rev. 2009, 38, 1802-1820.

[2] a) E. R. Kay, D. A. Leigh, F. Zerbetto, Angew. Chem. Int. Ed. 2007, 46, 72-191; b) G. Gil-Ramirez, D. A. Leigh, A. J. Stephens, Angew. Chem. Int. Ed. 2015, 54,6110-6150; c) M. Baroncini, S. Silvi, A. Credi, Chem. Rev. 2020, 120, 200-268.

[3] A. Coskun, M. Banaszak, R. D. Astumian, J. F. Stoddart, B. A. Grzybowski, Chem. Soc. Rev. 2012, 41, 19-30,

[4] S. J. Loeb, Chem. Soc. Rev. 2007, 36, 226-235.

[5] E. Lee, J. Heo, K. Kim, Angew. Chem. Int. Ed. 2000, 39, 2699-2701.

[6] Q. Li, C. H. Sue, S. Basu, A. K. Shveyd, W. Zhang, G. Barin, L. Fang, A. A. Sarjeant, J. F. Stoddart, O. M. Yaghi, Angew. Chem. Int. Ed. 2010, 49, 6751-6755.

[7] H. Deng, M. A. Olson, J. F. Stoddart, O. M. Yaghi, Nat. Chem. 2010, 2, 439-443.

[8] A. Coskun, M. Hmadeh, G. Barin, F. Gándara, Q. Li, E. Choi, N. L. Strutt, D. B. Cordes, A. M. Z. Slawin, J. F. Stoddart, J. P. Sauvage, O. M. Yaghi, Angew. Chem. Int. Ed. 2012, 51, 2160-2163.

[9] V. N. Vukotic, S. J. Loeb, Chem. Soc. Rev. 2012, 41, 5896-5906.

[10] K. Zhu, C. A. O’Keefe, V. N. Vukotic, R. W. Schurko, S. J. Loeb, Nat. Chem. 2015, 7, 514-519.

[11] V. N. Vukotic, K. J. Harris, K. Zhu, R. W. Schurko, S. J. Loeb, Nat. Chem. 2012, 4, 456-460.

[12] V. N. Vukotic, C. A. O’Keefe, K. Zhu, K. J. Harris, C. To, R. W. Schurko, S. J. Loeb, J. Am. Chem. Soc. 2015, 46, 9643-9651.

[13] K. Zhu, V. N. Vukotic, C. A. Okeefe, R. W. Schurko, S. J. Loeb, J. Am. Chem. Soc. 2014, 136, 7403-7409.

[14] Q. Chen, J. Sun, P. Li, I. Hod, P. Z. Moghadam, Z. S. Kean, R. Q. Snurr, J. T. Hupp, O. K. Farha, J. F. Stoddart, J. Am. Chem. Soc. 2016, 138, 14242-14245.

[15] P. R. McGonigal, P. Deria, I. Hod, P. Z. Moghadam, A.-J. Avestro, N. E. Horwitz, I. C. Gibbs-Hall, A. K. Blackburn, D. Chen, Y. Y. Botros, M. R. Wasielewski, R. Q. Snurr, J. T. Hupp, O. K. Farha, J. F. Stoddart, Proc. Natl. Acad. Sci. U. S. A. 2015, 112, 11161-11168;

[16] A. Saura-Sanmartin, A. Martinez-Cuezva, D. Bautista, M. R. B. Marzari, M. A. P. Martins, M. Alajarin, J. Berna, J. Am. Chem. Soc. 2020, 142, 13442-13449.

[17] A. P. Côté, A. I. Benin, N. W. Ockwig, M. O’Keeffe, A. J. Matzger, O. M. Yaghi, Science 2005, 310, 1166-1170.

[18] X. Feng, X. Ding, D. Jiang, Chem. Soc. Rev. 2012, 41, 6010-6022.

[19] C. S. Diercks, O. M. Yaghi, Science 2017, 355, 923.

[20] C. S. Diercks, O. M. Yaghi, Science 2017, 355, eaal1585.

[21] P. J. Waller, F. Gándara, O. M. Yaghi, Acc. Chem. Res. 2015, 48, 3053-3063.

[22] S. Kandambeth, K. Dey, R. Banerjee, J. Am. Chem. Soc. 2019, 141, 1807-1822.

[23] C. R. DeBlase, K. E. Silberstein, T.-T. Truong, H. D. Abruña, W. R. Ditchel, J. Am. Chem. Soc. 2013, 135, 1682116824.

[24] M. S. Lohse, T. Bein, Adv. Funct. Mater. 2018, 28, 175553.

[25] F. Haase, B. V. Lotsch, Chem. Soc. Rev. 2020, 49, 8469-8500.

[26] G. Das, S. K. Sharma, T. Prakasam, F. Gándara, R. Mathew, N. Alkhatib, N. Saleh, R. Pasricha, J.-C. Olsen, M. Baias, S. Kirmizialtin, R. Jagannathan, A. Trabolsi, Commun. Chem. 2019, 2, 106. https://doi.org/10.1038/s42004-019-0207-3.

[27] T. Ogoshi, S. Kanai, S. Fujinami, T. Yamagishi, J. Am. Chem. Soc. 2008, 130, 5022-5023.

[28] T. Ogoshi, T. Yamagishi, Y. Nakamoto, Chem. Rev. 2016, 116, 7937-8002. 
[29] S.-B. Yu, H. Lyu, H. Wang, D.-W. Zhang, Y. Liu, Z.-T. Li, Polym. Chem. 2016, 7, 3392-3397.

[30] G. Das, T. Skrojanc, S. K. Sharma, F. Gándra, M. Lusi, D. S. S. Rao, S. Vimala, S. K. Prasad, J. Raya, D. S. Han, R. Jagannathan, J.-C. Olsen, A. Trabolsi, J. Am. Chem. Soc. 2017, 139, 9558-9565.

[31] O. Buyukcakir, S. H. Je, S. N. Talapaneni, D. Kim, A. Coskun, ACS Appl. Mater. Interfaces 2017, 9, 7209-7216.

[32] P. Samanta, P. Chandra, S. Dutta, A. V. Desai, S. K. Ghosh, Chem. Sci. 2018, 9, 7874-7881.

[33] B. Cheng, A. E. Kaifer, J. Am. Chem. Soc. 2015, 137, 9788-9791.

[34] Zhu, M. Hong, D. Guo, J. Shi, Z. Tao, J. Chen, Z. Zhu, M. Hong, D. Guo, J. Shi, Z. Tao, J. Chen, J. Am. Chem. Soc. 2014, 136, 16461-16464.

[35] S. Kandambeth, A. Mallick, B. Lukose, M. V. Mane, T. Heine, R. Banerjee, J. Am. Chem. Soc. 2012, 134, 1952419527.

[36] B. P. Biswal, S. Chandra, S. Kandambeth, B. Lukose, T. Heine, R. Banerjee, J. Am. Chem. Soc. 2013, 135, 53285331.

[37] P. Langer, L. Yang, C. R. Pfeiffer, W. Lewis, N. R. Champness, Dalton Trans. 2019, 48, 58-64.

[38] B. Y. Xia, M. Xue, Chem. Commun. 2014, 50, 1021-1023.

[39] J. A. Riddle, S. P. Lathrop, J. C. Bollinger, D. Lee, J. Am. Chem. Soc. 2006, 128, 10986-10987.

[40] T. Ogoshi, T. Aoki, K. Kitajima, S. Fujinami, T. A. Yamagishi, Y. Nakamoto, J. Org. Chem. 2011, 76, $328-331$.

[41] a) Z. Gan, J. Magn. Reson. 2007, 184, 39-43; b) Z. Gan, J. P. Amoureux, J. Trébosc, Chem. Phys. Lett. 2007, 435, 163-169; c) R. Siegel, J. Trébosc, J. P. Amoureux, Z. Gan, J. Magn. Reson. 2008, 193, 321-325.

[42] P. Poizot, J. Gaubicher, S. Renault, L. Dubois, Y. Liang, Y. Yao, Chem. Rev. 2020, 120, 6490-6557.

[43] A. Jouhara, E. Quarez, F. Dolhem, M. Armand, N. Dupré, P. Poizot, Angew. Chem. Int. Ed. 2019, 58, 1568015684.

[44] S. Perticarari, T. Doizy, P. Soudan, C. Ewels, C. Latouche, D. Guyomard, F. Odobel, P. Poizot, J. Gaubicher, Adv. Energy Mater. 2019, 9, 1803688.

[45] S. Perticarari, Y Sayed-Ahmad-Baraza, C Ewels, P Moreau, D Guyomard, P. Poizot, F. Odobel, J. Gaubicher, Adv. Energy Mater. 2018, 8, 1701988.

[46] B. Genorio, K. Pirnat, R. Cerc-Korosec, R. Dominko, M. Gaberscek, Angew. Chem. Int. Ed. 2010, 49, 72227224.

[47] Z. Luo, L. Liu, J. Ning, K. Lei, Y. Lu, F. Li, J. Chen, Angew. Chem. Int. Ed. 2018, 57, 9443-9446.

[48] S. Xu, G. Wang, B. P. Biswal, M. Addicoat, S. Paasch, W. Shang, X. Zhuang, E. Brunner, T. Heine, R. Berger, X. Feng, Angew. Chem. Int. Ed. 2019, 58, 849-853.

[49] S. Jhulki, C. H. Feriante, R. Mysyk, A. M. Evans, A. Magasinski, A. Sankara Raman, K. Turcheniuk, S. Barlow, W. R. Dichtel, G. Yushin, S. R. Marder, ACS Appl. Energy Mater. 2021, 4, 350-356.

[50] K. Sakaushi, E. Hosono, G. Nickerl, T. Gemming, H. Zhou, S. Kaskel, J. Eckert, Nat. Commun. 2013, 4, 1485.

[51] S. Wu, W. Wang, M. Li, L. Cao, F. Lyu, M. Yang, Z. Wang, Y. Shi, B. Nan, S. Yu, Y. Sun, Y. Liu, Z. Lu, Nat. Commun. 2016, 7, 13318.

[52] S. Gu, S. Wu, L. Cao, M. Li, N. Qin, J. Zhu, Z. Wang, Y. Li, Z. Li, J. Chen, Z. Lu, J. Am. Chem. Soc. 2019, 141, 9623-9628.

[53] H. Li, M. Tang, Y. Wu, Y. Chen, S. Zhu, B. Wang, C. Jiang, E. Wang, C. Wang, J. Phys. Chem. Lett. 2018, 8, 3205-3211.

[54] T. Sun, J. Xie, W. Guo, D. S. Li, Q. Zhang, Adv. Energy Mater. 2020, 10, 1904199.

[55] P. Poizot, F. Dolhem, Energy Environ. Sci. 2011, 4, 2003-2019.

[56] H. Chen, M. Armand, M. Courty, M. Jiang, C. P. Grey, F. Dolhem, J. M. Tarascon, P. Poizot, J. Am. Chem. Soc. 2009, 131, 8984-8988.

[57] S. Renault, D. Brandell, K. Edström, ChemSusChem 2014, 7, 2859-2867. 

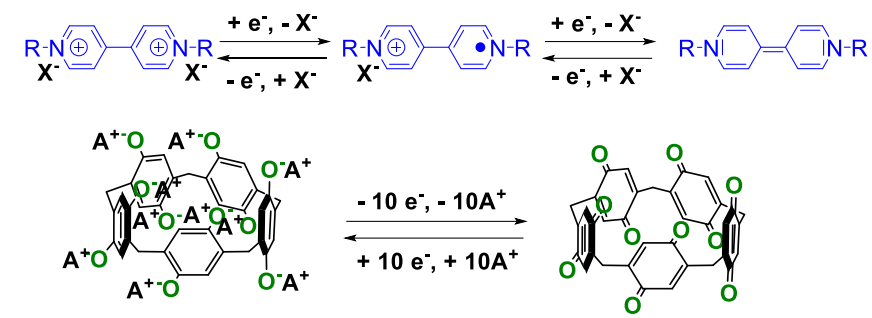

Scheme 1. Reversible one-electron reduction steps of the p-type viologen unit (top) and ideal electrochemical reversible process for the $n$-type $P[5] O A(A=H, L i)$ macrocycle.

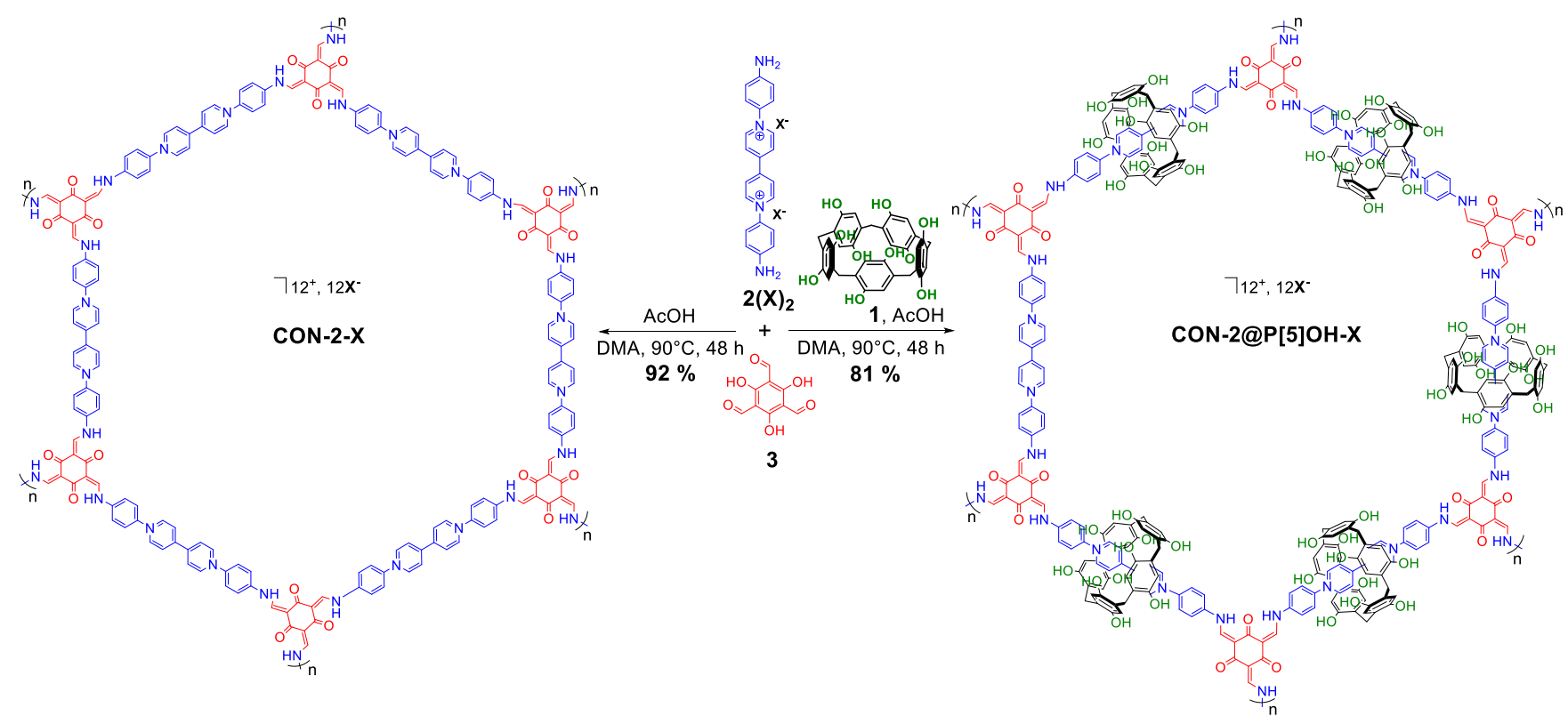

Scheme 2. Synthesis of CON-2-X and CON-2@P[5]OH-X (X $=\mathrm{ClO}_{4}$ or $\left.\mathrm{PF}_{6}\right)$.

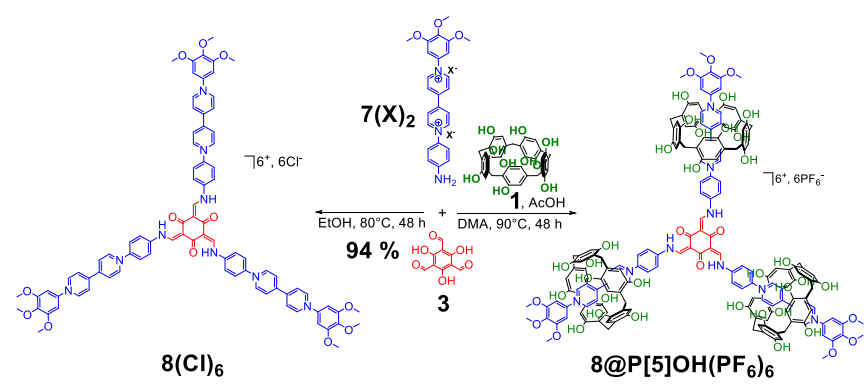

Scheme 3 Final steps for the synthesis of $8(\mathrm{Cl})_{6}$ and $8 @ \mathrm{P}[5] \mathrm{OH}\left(\mathrm{PF}_{6}\right)_{6}$. 


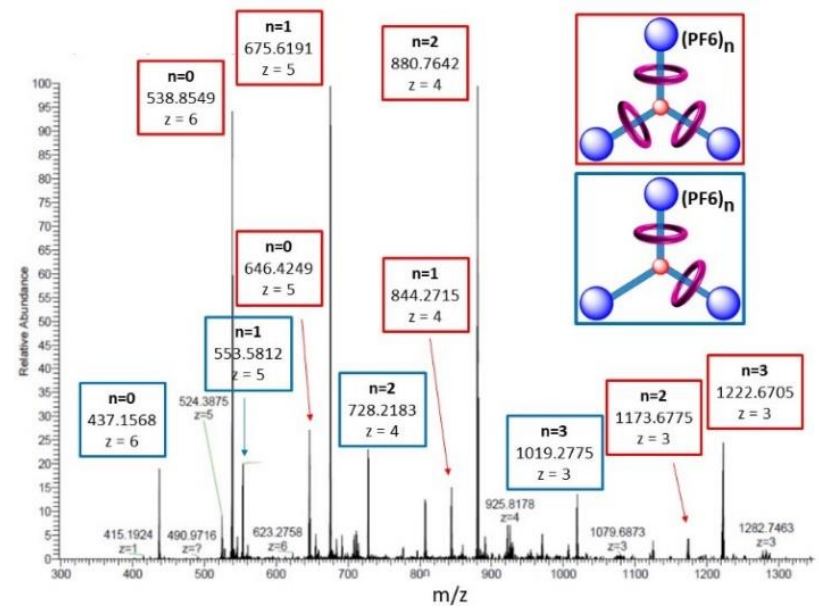

Figure 1. HR-ESIMS spectrum (ESI+ in $\mathrm{MeOH}$ ) of 8@P[5]OH( $\left.\mathrm{PF}_{6}\right)_{6}$ with the attribution of the different $\mathrm{m} / \mathrm{z}$ peaks ( $n$ is the number of $\mathrm{PF}_{6}{ }^{-}$counter-anions and $\mathrm{z}$ is the charge of the cation derived from the isotopic distribution). The major species [4]rotaxanes and minor species [3]rotaxane are schematically represented.

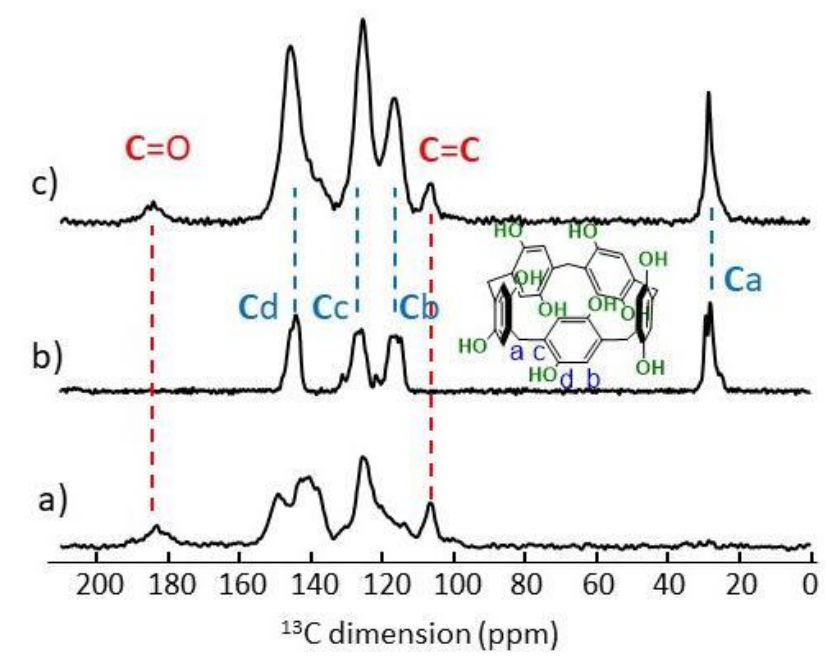

Figure 2. ${ }^{13} \mathrm{C}$ CPMAS NMR spectra of a) $\mathrm{CON}_{2}-\mathrm{PF}_{6}$, b) P[5]OH and c) CON-2@P[5]OH-PF . Caracteristic signals of the COF network and the $\mathrm{P}[5] \mathrm{OH}$ unit are shown in red and blue respectively.

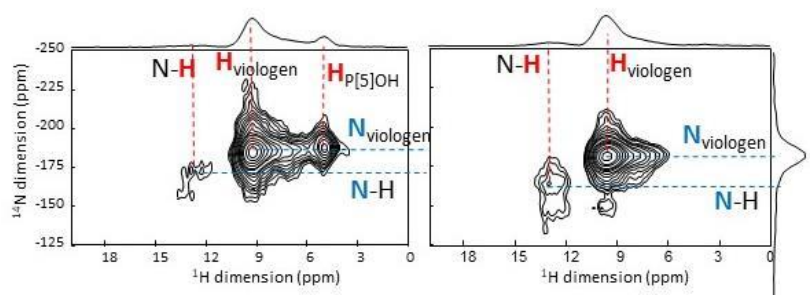

Figure 3. ${ }^{1} \mathrm{H}-{ }^{14} \mathrm{~N}$ 2D MAS NMR spectra of CON-2-PF 6 (left) and CON-2@P[5]OH-PF 6 (right). 

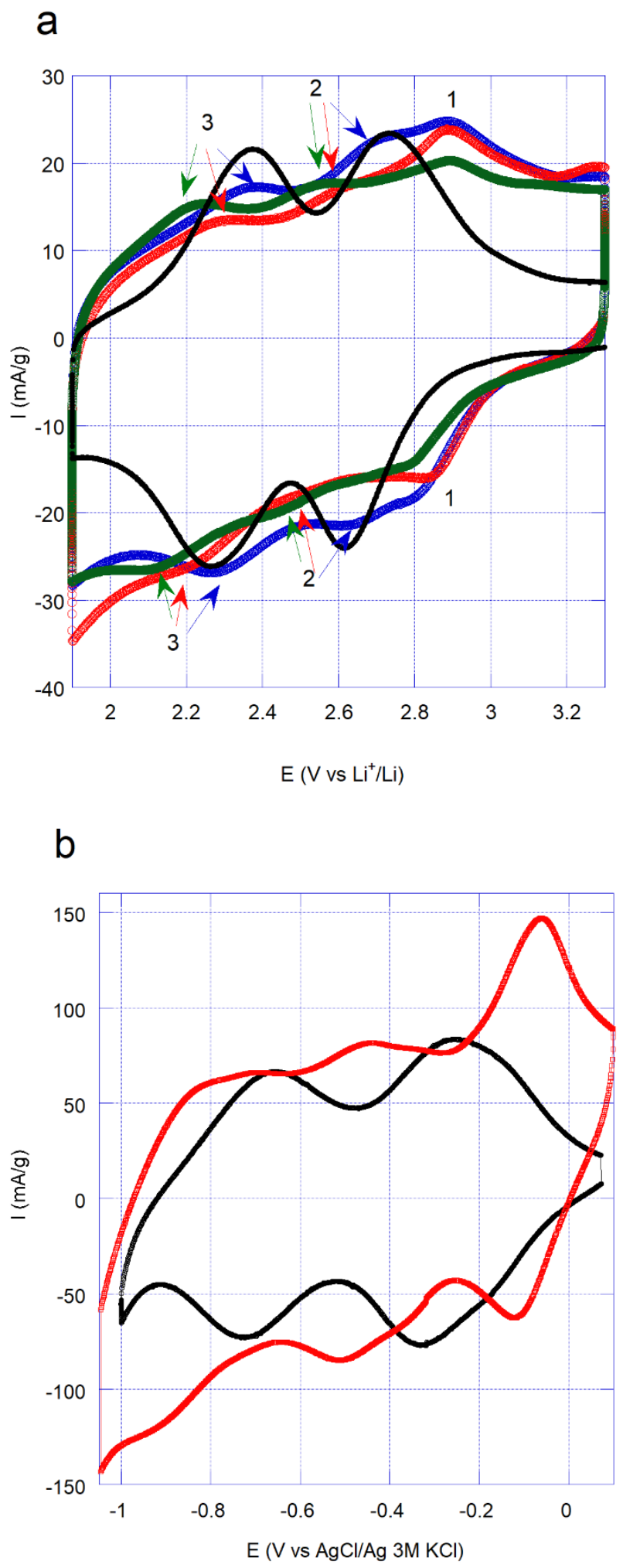

Figure 4. a) Cyclic voltammetry at $0.5 \mathrm{mV} / \mathrm{s}$ in $\mathrm{PC}$ based $\mathrm{LiClO}_{4}$ electrolytes at different concentrations for CON2-ClO ${ }_{4}$ in $1 \mathrm{M}$ (black) and CON-2@P[5]OH-ClO ${ }_{4}$ in 0.5M (blue), $1 \mathrm{M}$ (red) and 3.5M (green). The intensity of CON2-ClO ${ }_{4}$ has been divided by a factor of 2.5 to facilitate the comparison. b) cyclic voltammetry at $0.5 \mathrm{mV} / \mathrm{s}$ in $1 \mathrm{M}$ $\mathrm{LiClO}_{4}$ aqueous electrolyte (neutral pH) for $\mathrm{CON}_{-2}-\mathrm{ClO}_{4}$ (black) and $\mathrm{CON}-2 @ \mathrm{P}[5] \mathrm{OH}-\mathrm{ClO}_{4}$ (red). For the sake of clarity all voltammograms correspond to the second cycle, the first cycle showing the initial oxidation of the $\mathrm{P} 5[\mathrm{OH}]$ group being reported in Figure S54. 


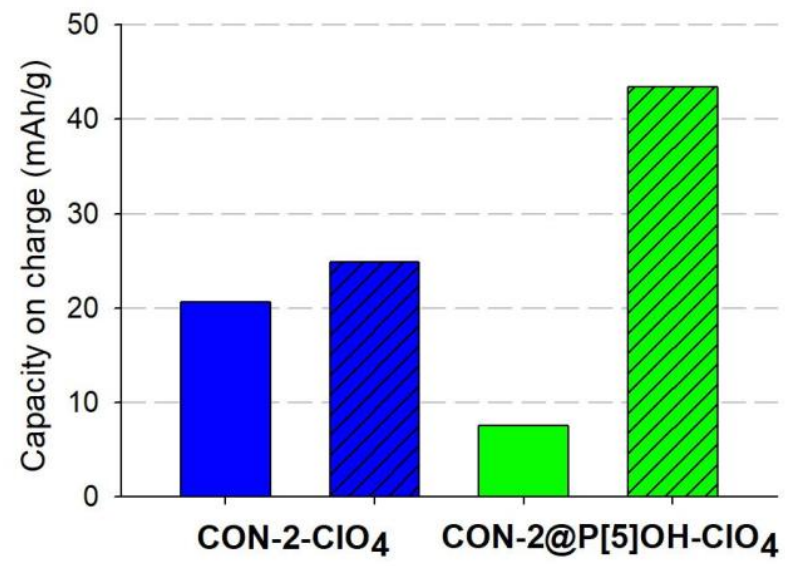

Figure 5. Specific capacity on charge (oxidation) of $\mathrm{CON}-2-\mathrm{ClO}_{4}$ (blue bars) and $\mathrm{CON}-2 @ \mathrm{P}[5] \mathrm{OH}-\mathrm{ClO}_{4}$ (green bars) in $1 \mathrm{M} \mathrm{LiClO}_{4}, \mathrm{PC}$ (plain bars) and aqueous electrolyte (striped bars). 